\title{
Sex differences in the prevalence of obesity in 800,000 Chinese adults with type 2 diabetes
}

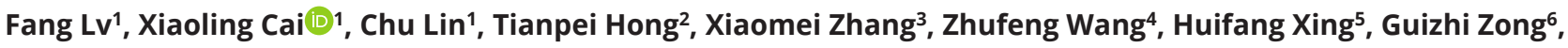 \\ Juming $\mathrm{Lu}^{7}$, Xiaohui Guo ${ }^{8}$, Jing $\mathrm{Wu}^{1}$, Leili Gao ${ }^{1}$, Xianghai Zhou' ${ }^{1}$, Xueyao $\mathrm{Han}^{1}$ and Linong ji ${ }^{1}$
}

${ }^{1}$ Department of Endocrinology and Metabolism, Peking University People's Hospital, Beijing, China

${ }^{2}$ Department of Endocrinology and Metabolism, Peking University Third Hospital, Beijing, China

${ }^{3}$ Department of Endocrinology, Peking University International Hospital, Beijing, China

${ }^{4}$ Department of Endocrinology and Metabolism, China Academy of Traditional Chinese Medicine Guanganmen Hospital, Beijing, China

${ }^{5}$ Department of Endocrinology and Metabolism, Beijing Mentougou Hospital, Beijing, China

${ }^{6}$ Department of Endocrinology and Metabolism, Beijing Jingmei Group General hospital, Beijing, China

${ }^{7}$ Department of Endocrinology, Chinese PLA General Hospital, Beijing, China

${ }^{8}$ Department of Endocrinology, Peking University First Hospital, Beijing, China

Correspondence should be addressed to X Cai or L Ji: dr_junel@sina.com or jiln@bjmu.edu.cn

\begin{abstract}
Aims: To estimate the sex differences in the prevalence of overweight and obesity aged 20-89 in Chinese patients with type 2 diabetes (T2D).

Methods: 811,264 patients with T2D from six hospital-based, cross-sectional studies, and 46,053 subjects from the general population were included in our analysis. Prevalence of underweight, overweight, obesity were calculated in each sex.

Results: In patients with $\mathrm{T} 2 \mathrm{D}$, the standardized prevalence of underweight (BMI $<18.5$ $\left.\mathrm{kg} / \mathrm{m}^{2}\right)$, overweight $\left(24 \mathrm{~kg} / \mathrm{m}^{2} \leq \mathrm{BMI}<28 \mathrm{~kg} / \mathrm{m}^{2}\right)$, and general obesity $\left(\mathrm{BMI} \geq 28 \mathrm{~kg} / \mathrm{m}^{2}\right)$ were $2.2 \%, 43.2 \%$, and $11.6 \%$, respectively. Similar trend patterns of the prevalence of underweight and overweight were observed in general and T2D population, in males and females with T2D (all $P$ for trend $<0.01$ ). In patients with T2D, patients at a younger age and older age were more likely to be underweight. The prevalence of overweight increased first, then stabilized or decreased with age. However, different trend patterns of the prevalence of obesity in males and females were found. In males, the prevalence of obesity decreased first, and then stabilized after 60 years of age. In females, the prevalence of obesity decreased first, then increased after 50 years of age. In the general population, the prevalence of obesity increased with age in females, while, the trend of prevalence of obesity with age in males was not obvious.

Conclusion: Different trends in the prevalence of obesity with age in different sex were found in Chinese patients with T2D.
\end{abstract}

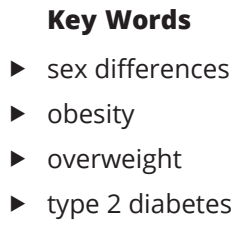

Endocrine Connections (2021) 10, 139-145

\section{Introduction}

It was well-known that the prevalence of overweight and obesity is increasing worldwide. It was reported that $39 \%$ of adults aged more than 18 years were overweight, and about $13 \%$ of the world's adult population were obese in 2016 (Obesity and overweight. https://www.who.int/en/ news-room/fact-sheets/detail/obesity-and-overweight. 1 April 2020). It was also suggested that the epidemic of obesity and overweight (1) was associated with the increased risk of type 2 diabetes (T2D) $(2,3)$. In China, approximately $31.3-37.1 \%$ of patients with T2D were obese or overweight $(4,5,6)$.

As obesity was one of the risk factors for cardiovascular diseases (CVD) in patients with T2D, management of body weight was highly recommended. https://ec.bioscientifica.com https://doi.org/10.1530/EC-20-0547 (c) 2021 The authors Published by Bioscientifica Ltd
This work is licensed under a Creative Commons Attribution-NonCommercial-NoDerivatives 4.0 enternationad ticense ifica.com at 04/26/2023 01:38:39AM 
It was demonstrated that weight loss could result in various metabolic benefits, including glycemic control, blood pressure improvement, and lipid profile management $(7,8,9)$. In patients with $\mathrm{T} 2 \mathrm{D}$, weight loss was associated with a reduced risk of CVD $(10,11)$. Therefore, curbing or reversing BMI in a reasonable range is quite important, which might affect the medical resources utilization and health care policies making, especially in people with diabetes.

To fulfill the management of body weight in patients with T2D, it is important to understand the trends in the prevalence of obesity and overweight with age. So far, few studies estimated the obesity trends with age in the overall population. In a Chinese population, it was found that men ages 45-54 years had the highest prevalence of overweight and obesity, whereas the prevalence varied among age groups in women in general population (12). It was also observed that males reached their highest prevalence of obesity at 45-54 years of age, whereas females had the highest obesity prevalence at 55-64 years in a southern China population (13). However, data of the distribution trend in BMI stratified by sex and age in Chinese patients with T2D is lacking.

Therefore, our aims were to delineate the trends in BMI and the trends in the prevalence of overweight, obesity with age in Chinese male and female patients with T2D, which we believe would provide useful guidance on intervention strategies for weight control and nutrition management in T2D.

\section{Methods}

\section{Study design}

We used data from several studies to describe the trends of BMI and prevalence of underweight, overweight, and obesity among Chinese patients with T2D, aged 20-89 years. The China National Diabetes and Metabolic Disorders Study (conducted in 2007-2008) was used as a reference data for general population in China. We used data sets for patients with T2D from six studies: China National HbA1c Surveillance System (CNHSS) from 2009 to 2012, China Cardiometabolic Registries 3B study (CCMR-3B, conducted in 2010-2011), and ChinaDiaLEAD (conducted in 2016). The inclusion criteria was as following: participants with T2D aged 20-89 years; participants with available data on age, sex and detailed physical examination (e.g. weight and height). The exclusion criteria was as following: those being pregnant or lactating at the time of survey; and those with missing or implausible outlying data.

The design and data of the seven studies have been published previously $(14,15,16,17,18,19)$. In brief, the China National Diabetes and Metabolic Disorders Study, conducted from June 2007 through May 2008, was a cross-sectional study designed to provide reliable data on the prevalence of diabetes and associated metabolic risk factors in the adult population in China. This study used a complex multistage stratified sampling method according to geographical region, economic development status, and degree of urbanization. CNHSS study was launched by the Chinese Diabetes Society in 2009 to monitor glycemic control in outpatients with T2D in China. The CCMR-3B was an observational, cross-sectional, multicenter study, conducted across China from August 2010 to March 2011 with the aim to investigate blood glucose, blood lipid, and blood pressure control status in patients with T2D. China-DiaLEAD was a cross-sectional study that aimed to assess the epidemiological characteristics of lower extremity arterial disease in Chinese diabetes patients at high risk. The number of participants and the inclusion and exclusion criteria for each study were collected in Supplementary Table 1 (see section on supplementary materials given at the end of this article).

All the studies were approved by the institutional review board or independent ethics committee of each participating institution. All participants gave written informed consent.

\section{Measures and definitions}

Weight and height were measured following standardized protocols from the World Health Organization (WHO) or self-reported. BMI was calculated as weight in kilograms divided by height in meters squared. The BMI cutoff points were recommended by WHO and Working Group for Obesity in China (WGOC) (20), which were used to define underweight, normal weight, overweight and obesity. Using the WHO criteria, normal weight was $18.5 \mathrm{~kg} / \mathrm{m}^{2} \leq \mathrm{BMI}<25 \mathrm{~kg} / \mathrm{m}^{2}$, overweight was defined as $25 \mathrm{~kg} / \mathrm{m}^{2} \leq \mathrm{BMI}<30 \mathrm{~kg} / \mathrm{m}^{2}$, and obesity as BMI $\geq 30 \mathrm{~kg} / \mathrm{m}^{2}$. Using the WGOC criteria, normal weight was defined as $18.5 \mathrm{~kg} / \mathrm{m}^{2} \leq \mathrm{BMI}<24 \mathrm{~kg} / \mathrm{m}^{2}$, overweight as $24 \mathrm{~kg} / \mathrm{m}^{2} \leq \mathrm{BMI}<28 \mathrm{~kg} / \mathrm{m}^{2}$ and obesity as BMI $\geq 28 \mathrm{~kg} / \mathrm{m}^{2}$. In both criteria underweight was defined as $\mathrm{BMI}<18.5 \mathrm{~kg} / \mathrm{m}^{2}$.

Established cardiovascular disease (CVD) was defined as the presence of coronary heart disease or 
stroke or peripheral artery disease. Previous coronary heart disease and date of diagnosis were retrieved from the patient database. Coronary heart disease included ischemic heart disease with abnormal ECG or stress test, myocardial infarction with typical changes in ECG and plasma enzyme testing, coronary revascularization, percutaneous transluminal coronary angioplasty, or coronary atherectomy. Stroke included ischemic or hemorrhagic stroke - that is, subarachnoid hemorrhage, intracerebral hemorrhage, and other or unspecified intracranial hemorrhage, irrespective of whether the patient had completely or incompletely recovered. Cardiovascular disease was defined as having either coronary heart disease or stroke. Peripheral vascular disease was defined as intermittent claudication, foot ulcer, or amputation. Nephropathy was defined as the presence of albuminuria and low glomerular filtration rate (defined as eGFR $<30 \mathrm{~mL} / \mathrm{min} / 1.73 \mathrm{~m}^{2}$ ). The diagnosis retinopathy was confirmed by eye exams, included nonproliferative diabetic retinopathy and proliferative diabetic retinopathy.

\section{Statistical analysis}

Data were presented as mean \pm standard deviation (SD) for continuous variables and as proportions for categorical variables. Analyses were stratified by sex (males and females), age group (20-29, 30-39, 40-49, 50-59, 60-69, 70-79, 80-89 years), history of CVD and four quartiles of diabetes duration. Prevalence of underweight, overweight and obesity was calculated and stratified on the basis of sex, and age. Direct standardization was performed using the Chinese population structure in 2010 aged 20-89 years, and prevalence of diabetes at different age and sex reported in 2007-2008 (14).In this study, the prevalence of T2D at 70-79 years, and 80-89 years were approximately equivalent to the prevalence of patient aged more than 70 years. Comparisons were statistically analyzed using one-way ANOVA and chisquared tests. The linear-by-linear association test was used to analyze the trend of prevalence over various age groups. Statistical analysis was performed using SPSS software (version 20.0, SPSS Corp). $P$ value $<0.05$ for the two-tailed test was considered as statistically significant.

\section{Results}

Totally, 811,264 patients with T2D from six hospitalbased, cross-sectional studies, and 46,053 subjects from general population were included in our analysis.
The clinical characteristics of included participants in each study were presented in Supplementary Table 2.

\section{Clinical characteristics and diabetes complications categorized by BMI groups}

Clinical characteristics, such as age, duration of diabetes, HbA1c, blood pressure, and lipid profiles, as well as diabetes complications categorized by the groups of underweight, normal weight, overweight and obesity were shown in Table 1 . The levels of systolic blood pressure, diastolic blood pressure, cholesterol, triglycerides, and the percentage of CVD, retinopathy, and nephropathy in the obesity group were the highest one among the four BMI groups (all $P<0.001$ ). The values of systolic and diastolic blood pressure, cholesterol, triglycerides, low density lipoprotein cholesterol, and the prevalence of CVD, retinopathy, and nephropathy increased with BMI category increased $(P$ for trend $<0.001)$. In addition, the levels of systolic blood pressure, diastolic blood pressure, cholesterol, and triglycerides in general population were lower than that in patients with T2D (all $P<0.001$ ).

\section{Prevalence of underweight, normal weight, overweight and obesity}

For patients with T2D, the mean age was $58.9 \pm 11.5$ years with the mean BMI of $24.4 \pm 3.1 \mathrm{~kg} / \mathrm{m}^{2}$, males accounted for $52.4 \%$ of the patients. The standardized prevalence of underweight in patients with T2D was $2.2 \%$. According to WHO criteria, the standardized prevalence of overweight and obesity was 34.6 and $4.4 \%$, respectively. According to WGOC standard, the standardized prevalence of overweight and obesity as 43.0 and $11.6 \%$, respectively.

For general population, the mean age was $45.0 \pm 13.7$ years, younger than patients with T2D $(P<0.001)$. Males accounted for $39.9 \%$ of the patients. The mean BMI was $24.1 \pm 3.7 \mathrm{~kg} / \mathrm{m}^{2}$, and was lower than that in patients with T2D $(P<0.001)$. According to WGOC standard, the prevalence of underweight $(4.7 \%)$ and general obesity (14.5\%) were higher, while, the prevalence of overweight (32.6\%) was lower in general population than that in patients with T2D (all $P<0.001$ ).

Trends in BMI, prevalence of underweight, overweight and obesity with age

In patients with $\mathrm{T} 2 \mathrm{D}$, there was a significant difference in the trends of BMI with age stratified by sex 
Table 1 Clinical characteristics categorized by four BMI groups in this pooled analysis with type 2 diabetes.

\begin{tabular}{|c|c|c|c|c|c|c|c|c|}
\hline & \multirow{2}{*}{$\begin{array}{c}\text { General } \\
\text { population }\end{array}$} & \multirow{2}{*}{$\begin{array}{l}\text { Patients } \\
\text { with T2D }\end{array}$} & \multirow[b]{2}{*}{ P value } & \multicolumn{4}{|c|}{ BMI categories } & \multirow[b]{2}{*}{$P$ value } \\
\hline & & & & $<18.5 \mathrm{~kg} / \mathrm{m}^{2}$ & $18.5-23.9 \mathrm{~kg} / \mathrm{m}^{2}$ & $24-27.9 \mathrm{~kg} / \mathrm{m}^{2}$ & $\geq 28 \mathrm{~kg} / \mathrm{m}^{2}$ & \\
\hline Patients $(n, \%)$ & 46,053 & 81,1264 & & $16,017(2.0 \%)$ & $352,833(43.5 \%)$ & $353,088(43.5 \%)$ & $89,326(11.0 \%)$ & \\
\hline Male sex $(n, \%)$ & 18,355 (39.9\%) & $424,810(52.4 \%)$ & $<0.001$ & 6755 (42.2\%) & 180,577 (51.2\%) & $195,611(55.4 \%)$ & 41,867 (46.9\%) & $<0.001$ \\
\hline Age (years) & $45.0 \pm 13.7$ & $58.9 \pm 11.5$ & $<0.001$ & $59.4 \pm 13.2$ & $59.8 \pm 11.5$ & $59.5 \pm 11.2$ & $59.1 \pm 12.1$ & $<0.001$ \\
\hline Duration (years) & I & $5.7 \pm 5.3$ & I & $6.0 \pm 6.0$ & $5.7 \pm 5.3$ & $5.7 \pm 5.3$ & $6.2 \pm 5.7$ & $<0.001$ \\
\hline Weight (kg) & $63.2 \pm 11.7$ & $67.2 \pm 10.6$ & $<0.001$ & $47.3 \pm 5.1$ & $60.7 \pm 7.1$ & $70.9 \pm 7.3$ & $81.5 \pm 10.4$ & $<0.001$ \\
\hline BMI $\left(\mathrm{kg} / \mathrm{m}^{2}\right)$ & $24.1 \pm 3.7$ & $24.4 \pm 3.1$ & $<0.001$ & $17.4 \pm 1.0$ & $22.0 \pm 1.4$ & $25.7 \pm 1.1$ & $30.2 \pm 2.7$ & $<0.001$ \\
\hline $\begin{array}{l}\text { Glycated } \\
\text { hemoglobin (\%) }\end{array}$ & I & $7.85 \pm 1.77$ & I & $8.31 \pm 2.39$ & $7.83 \pm 1.91$ & $7.87 \pm 1.77$ & $8.02 \pm 1.81$ & $<0.001$ \\
\hline $\begin{array}{l}\text { systolic blood } \\
\text { pressure (mmHg) }\end{array}$ & $122 \pm 19$ & $132 \pm 15$ & $<0.001$ & $127 \pm 17$ & $129 \pm 15$ & $133 \pm 15$ & $136 \pm 16$ & $<0.001$ \\
\hline $\begin{array}{l}\text { diastolic blood } \\
\text { pressure }(\mathrm{mmHg})\end{array}$ & $78 \pm 11$ & $81 \pm 11$ & $<0.001$ & $77 \pm 11$ & $79 \pm 10$ & $81 \pm 10$ & $83 \pm 11$ & $<0.001$ \\
\hline $\begin{array}{l}\text { Total cholesterol } \\
(\mathrm{mmol} / \mathrm{L})\end{array}$ & $4.72 \pm 0.99$ & $4.77 \pm 1.44$ & $<0.001$ & $4.51 \pm 1.35$ & $4.75 \pm 1.34$ & $4.92 \pm 1.32$ & $5.04 \pm 1.41$ & $<0.001$ \\
\hline $\begin{array}{l}\text { Triglycerides } \\
\text { (mmol/L) }\end{array}$ & $1.55 \pm 1.13$ & $2.19 \pm 1.60$ & $<0.001$ & $1.85 \pm 1.39$ & $1.99 \pm 1.49$ & $2.20 \pm 1.60$ & $2.42 \pm 1.84$ & $<0.001$ \\
\hline HDL-C (mmol/L) & $1.34 \pm 0.34$ & $1.43 \pm 0.73$ & $<0.001$ & $1.56 \pm 0.75$ & $1.46 \pm 0.75$ & $1.41 \pm 0.70$ & $1.38 \pm 0.75$ & $<0.001$ \\
\hline LDL-C (mmol/L) & $2.76 \pm 0.85$ & $2.89 \pm 1.23$ & $<0.001$ & $2.96 \pm 1.67$ & $2.71 \pm 0.96$ & $2.79 \pm 0.96$ & $2.88 \pm 1.04$ & $<0.001$ \\
\hline \multicolumn{9}{|l|}{$\begin{array}{l}\text { Diabetes } \\
\text { complications }\end{array}$} \\
\hline $\operatorname{CVD}(n, \%)$ & l & $126,628(15.6 \%)$ & l & $2129(13.3 \%)$ & $47,126(13.4 \%)$ & $58,098(16.5 \%)$ & 19,275 (21.6\%) & $<0.001$ \\
\hline Retinopathy $(n, \%)$ & I & 65,327 (8.1\%) & l & $1370(8.6 \%)$ & 26,402 (7.5\%) & 28,309 (8.0\%) & $9246(10.4 \%)$ & $<0.001$ \\
\hline Nephropathy $(n, \%)$ & l & $66,153(8.2 \%)$ & l & $1386(8.7 \%)$ & $25,992(7.4 \%)$ & $29,116(8.2 \%)$ & $9659(10.8 \%)$ & $<0.001$ \\
\hline
\end{tabular}

CVD, cardiovascular disease; CNHSS, China National HbA1c Surveillance System; CCMR-3B, China Cardiometabolic Registries 3B study.

( $P$ for trend $<0.001)$. In males, the mean BMI level gradually declined with age. In females, the mean BMI level gradually increased from 20 to 29 years of age, then peaked at 70-79 years of age (Fig. 1). The trends in BMI with age was significantly different between general populations and T2D. For general population, the mean BMI increased gradually and stabilized after middle age or old age (Fig. 1).

Similar trends in the prevalence of underweight with age were observed between males and females ( $P$ for trend $<0.01)$. Patients at young age or old age were more likely to be underweight in both males and females with T2D (Fig. 2). The trend in the prevalence of underweight with age in general population was similar to that in patients with T2D (Supplementary Fig. 1).

Similar trends in the prevalence of overweight with age were observed in males and females.
In males, the prevalence of overweight increased first, then stabilized after 50 years of age $(P$ for trend $<0.001$ ). In females, the prevalence of overweight increased with age, and decreased after 70 years of age ( $P$ for trend $<0.001$ ) (Fig. 2). The trend in the prevalence of overweight with age in general population was similar to that in patients with T2D (Supplementary Fig. 1).

Different trend patterns in the prevalence of obesity in males and females with T2D were observed. In males, the prevalence of obesity decreased first, and then stabilized after 60 years of age $(P$ for trend $<0.001)$. In females, the prevalence of obesity decreased first, then increased after 50 years of age, and had a trend to decline after 80 years ( $P$ for trend $<0.001$ ) (Fig. 2 ). There was significant difference between general and T2D population in the trends of the prevalence of obesity with age. In general population, the prevalence of obesity increased with age in females. However, age-stratified analysis did not reveal
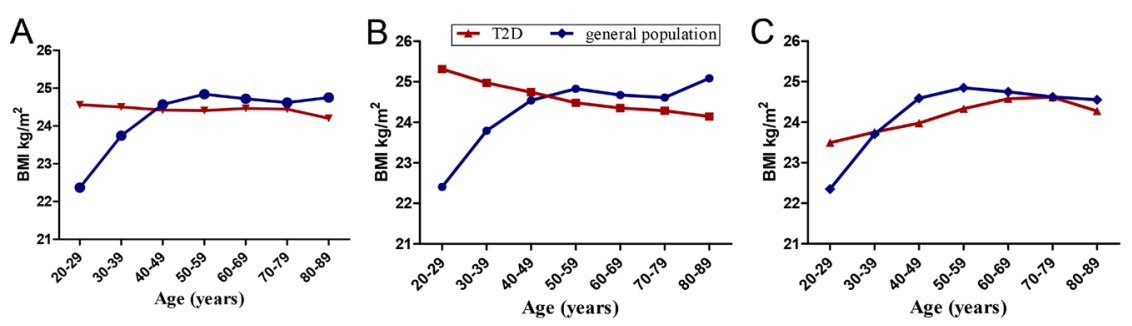

\section{Figure 1}

Trends of BMI with age in total (A), male (B) and female (C) adults with type 2 diabetes and general population in China (all $P$ for trend $<0.01$ ). https://ec.bioscientifica.com https://doi.org/10.1530/EC-20-0547
(C) 2021 The authors Published by Bioscientifica Ltd
This work is licensed under a Creative Commons Attribution-NonCommercial-NoDerivatives 4.0 elnternationab ficense ifica.com at 04/26/2023 01:38:39AM 

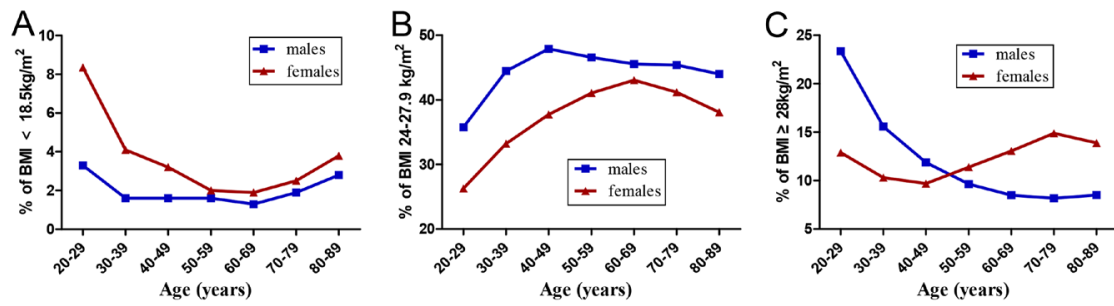

Figure 2

Trends in the prevalence of underweight, overweight and obesity with age in male and female patients with type 2 diabetes in China. (A) Trends in the prevalence of underweight with age stratified by sex ( $P$ for trend<0.01). (B) Trends in the prevalence of overweight with age stratified by sex ( $P$ for trend $<0.01$ ). (C) Trends in the prevalence of obesity with age stratified by sex ( $P$ for trend $<0.01$ in males). According to the WGOC criteria: underweight was defined as $\mathrm{BMI}<18.5 \mathrm{~kg} / \mathrm{m}^{2}$, overweight as $24 \mathrm{~kg} / \mathrm{m}^{2} \leq$ $\mathrm{BMI}<28 \mathrm{~kg} / \mathrm{m}^{2}$ and obesity as $\mathrm{BMI} \geq 28 \mathrm{~kg} / \mathrm{m}^{2}$. obvious trend of the prevalence of obesity in males ( $P$ for trend $>0.05$ ) (Supplementary Fig. 1).

The trends in the prevalence of obesity with age did not changed significantly in male patients with T2D when stratified by the history of CVD (Supplementary Fig. 2 ). We also observed similar trends in the prevalence of obesity with age in patients with first, second and third quartile of diabetes duration (Supplementary Fig. 3).

\section{Discussion}

Our study estimated the mean BMI and the prevalence of underweight, overweight, obesity in Chinese patients with T2D by using hospital-based national survey data sources with 811,264 adult participants. Patients with higher BMI had relatively worse metabolic markers, including blood pressure and lipids profiles. Trends in the prevalence of obesity with age between general and T2D population were significant different. Trends in the prevalence of obesity with age between males and females were also with significant difference in Chinese T2D patients.

According to this study, we observed different trends in the prevalence of obesity with age between males and females, both in patients with T2D and in general population. Obesity might be influenced by many factors, such as genetics, cultures, lifestyles, sex hormones, environments, and socioeconomic status (21). As for sex- and age-difference in the trend of BMI, it was supposed that, younger males generally have more fat-free muscle compared with females $(22,23)$, which might exhibit higher BMI in younger males. Aging, in particular menopause transition with loss of estrogen production, was associated with a preferential increase of abdominal fat in females (24). A continuous decrease in lean mass with age in both females and males (although more striking for the latter) could result in decreased BMI with age (25). The mechanisms of obesity might be more complex in patients with T2D since certain lifestyle modifications, hypoglycemic drugs, and the associated complications might affect the body weight in T2D. These reasons above may explain sex and age difference of prevalence of obesity between patients with T2D and the general population.

Few studies evaluated age- or sex-difference of BMI in patients with T2D. Hillier et al. observed a striking inverse linear relation between BMI and age at diagnosis of T2D in a population-based study of 2437 patients newly diagnosed with type 2 diabetes. Average BMI decreased from $38.3 \mathrm{~kg} / \mathrm{m}^{2}$ in the youngest age group to $28.8 \mathrm{~kg} / \mathrm{m}^{2}$ in the oldest age group (26). However, this study did not describe the trend of BMI with age in males and females separately. Further prospective studies with longer term follow-up and specific attention to BMI trend may enhance our understanding of the trends of BMI with age in different sex.

Learning the different trends in the prevalence of obesity with age should have important clinical implications. There seemed to be a natural tendency to lose weight with age in males. It was supposed that treatment for obesity was more complex in the elderly population when compared with the general population, since that the 'elderly' included various groups with different levels of overall health (27). Therefore, it should be wondered if intensive weight control was appropriately employed in old male patients. In addition, to avoid increasing the risk for mortality, management of body weight should not be over-stressed when certain complications occurred or at certain ages. According to our results, the prevalence of overweight and obesity in females was increased with age until 80 years, which might suggest that weight management in females should be active and be kept for the whole life.

In our study, we found the levels of systolic blood pressure, diastolic blood pressure, total cholesterol, triglycerides, and diabetes complications were highest in T2D patients with obesity, indicating that obesity resulted in relatively worse metabolic profiles. As obesity is an
This work is licensed under a Creative Commons Attribution-NonCommercial-NoDerivatives 4.0 Internationab ficense.ifica.com at 04/26/2023 01:38:39AM 
important cardiovascular risk factor in the assessment and treatment of cardiovascular disease (CVD) (28), curbing or reversing $\mathrm{BMI}$ in a reasonable range in $\mathrm{T} 2 \mathrm{D}$ patients is of vital importance, and should be an essential target for Chinese T2D patients besides the management of glucose control, blood pressure control, and lipids control.

Our study had clinical implications and strengths. Firstly, this study was based on six hospital-based national surveys designed to be the representatives of the adult patients with T2D in China, which allowed us to explore BMI within detailed clusters of sex, and age. Evidence for the prevalence of overweight and obesity in Chinese patients with type 2 diabetes added the urgency of the need for prevention of obesity and management of body weight. Secondly, in this study, we observed different trends in the prevalence of obesity with age in males and females with T2D, which might give the evidence for building up the health promotion strategies in T2D.

However, our study had several limitations. First, we did not have information available on the reasons for weight loss with age. Unintentional weight loss is generally indicative of deteriorating health and is associated with all-cause and cardiovascular mortality. We could not distinguish between intentional weight loss and unintentional weight loss. Secondly, we did not analyze if the type of glucose-lowering treatment might alter weight. Some variables, including education level, detailed dietary habits, family income, smoking and physical activity, were also not included for analyses. Thirdly, there were various indices used to assess obesity, such as BMI, waist circumference, waist-to-hip ratio, and total adipose tissue (TAT) of the abdomen assessed by CT or MRI. Though BMI was not the best marker to differentiate between fat, muscle and skeletal weight, BMI was the most practical one. In this study, we only used BMI as an index of obesity. More studies with better evaluation of waist circumference, waist-to-hip ratio and adipose tissue of the abdomen are needed to plan health services in T2D. Fourthly, measurement methods of blood lipids were not unified in different studies, and the inconsistent measurement methods might cause bias in research results.

\section{Conclusion}

By using 811,264 individual data of adult patients with T2D in China, we observed different trends in the level of BMI with age in males and females with T2D.
We also found that the trends in the prevalence of obesity were different with age in males and females patients. Results from this study provided evidence that different sex, and age should be taken full consideration when designing effective preventive intervention strategies for weight control and nutrition management in Chinese patients with T2D.

\section{Supplementary materials}

This is linked to the online version of the paper at https://doi.org/10.1530/ EC-20-0547.

\section{Declaration of interest}

Linong Ji has received fees for lecture presentations and consulting fees from AstraZeneca, Merck, Novartis, Novo Nordisk, Lilly, Roche, SanofiAventis and Takeda, and grants/research support from AstraZeneca, Merck, Novartis, Novo Nordisk and Sanofi-Aventis; no other relationships or activities that could appear to have influenced the submitted work.

\section{Funding}

This work was supported by National Natural Science Foundation of China (Nos. 81970698, 81900805, and 81970708), National Key Research and Development Program (No. 2016YFC1304901) of China.

\section{Data sharing}

No additional data available.

\section{Acknowledgements}

The authors thank all the staff who did work in China National HbA1C Surveillance System from 2009 to 2012, China Cardiometabolic Registries 3B study, China-DiaLEAD, and China National Diabetes and Metabolic Disorders Study.

\section{References}

1 NCD Risk Factor Collaboration (NCD-RisC). Trends in adult bodymass index in 200 countries from 1975 to 2014: a pooled analysis of 1698 population-based measurement studies with 19.2 million participants. Lancet 2016387 1377-1396. (https://doi.org/10.1016/ S0140-6736(16)30054-X)

2 Tirosh A, Shai I, Afek A, Dubnov-Raz G, Ayalon N, Gordon B, Derazne E, Tzur D, Shamis A, Vinker S, et al. Adolescent BMI trajectory and risk of diabetes versus coronary disease. New England Journal of Medicine 2011364 1315-1325. (https://doi.org/10.1056/ NEJMoa1006992)

3 Saeedi P, Petersohn I, Salpea P, Malanda B, Karuranga S, Unwin N, Colagiuri S, Guariguata L, Motala AA, Ogurtsova K, et al. Global and regional diabetes prevalence estimates for 2019 and projections for 2030 and 2045: results from the International Diabetes Federation Diabetes Atlas, 9th edition. Diabetes Research and Clinical Practice 2019157 107843. (https://doi.org/10.1016/j.diabres.2019.107843)

4 Xu Y, Wang L, He J, Bi Y, Li M, Wang T, Wang L, Jiang Y, Dai M, Lu J, et al. Prevalence and control of diabetes in Chinese adults. Journal of the American Medical Association 2013310 948-959. (https://doi. org/10.1001/jama.2013.168118) 
5 Wang L, Gao P, Zhang M, Huang Z, Zhang D, Deng Q, Li Y, Zhao Z, Qin X, Jin D, et al. Prevalence and ethnic pattern of diabetes and prediabetes in China in 2013. Journal of the American Medial Association 2017317 2515-2523. (https://doi.org/10.1001/ jama.2017.7596)

6 Li Y, Teng D, Shi X, Qin G, Qin Y, Quan H, Shi B, Sun H, Ba J, Chen $\mathrm{B}$, et al. Prevalence of diabetes recorded in mainland China using 2018 diagnostic criteria from the American Diabetes Association: national cross sectional study. BMJ 2020369 m997. (https://doi.org/10.1136/bmj.m997)

7 Stevens VJ, Obarzanek E, Cook NR, Lee IM, Appel LJ, Smith West D, Milas NC, Mattfeldt-Beman M, Belden L, Bragg C, et al. Long-term weight loss and changes in blood pressure: results of the trials of hypertension prevention, phase II. Annals of Internal Medicine 2001 134 1-11. (https://doi.org/10.7326/0003-4819-134-1-20010102000007)

8 Boulé NG, Haddad E, Kenny GP, Wells GA \& Sigal RJ. Effects of exercise on glycemic control and body mass in type 2 diabetes mellitus: a meta-analysis of controlled clinical trials. JAMA 2001286 1218-1227. (https://doi.org/10.1001/jama.286.10.1218)

9 Aucott L, Gray D, Rothnie H, Thapa M \& Waweru C. Effects of lifestyle interventions and long-term weight loss on lipid outcomes: a systematic review. Obesity Reviews 201112 e412-e425. (https://doi. org/10.1111/j.1467-789X.2010.00819.x)

10 Look AHEAD Research Group, Gregg EW, Jakicic JM, Blackburn G, Bloomquist P, Bray GA, Clark JM, Coday M, Curtis JM, Egan C, et al. Association of the magnitude of weight loss and changes in physical fitness with long-term cardiovascular disease outcomes in overweight or obese people with type 2 diabetes: a post-hoc analysis of the Look AHEAD randomised clinical trial. Lancet: Diabetes and Endocrinology 20164 913-921. (https://doi.org/10.1016/S2213-8587(16)30162-0)

11 Strelitz J, Ahern AL, Long GH, Hare MJL, Irving G, Boothby CE, Wareham NJ \& Griffin SJ. Moderate weight change following diabetes diagnosis and 10 year incidence of cardiovascular disease and mortality. Diabetologia 201962 1391-1402. (https://doi. org/10.1007/s00125-019-4886-1)

12 Reynolds K, Gu D, Whelton PK, Wu X, Duan X, Mo J, He J \& InterASIA Collaborative Group. Prevalence and risk factors of overweight and obesity in China. Obesity 200715 10-18. (https:// doi.org/10.1038/oby.2007.527)

13 Hu L, Huang X, You C, Li J, Hong K, Li P, Wu Y, Wu Q, Wang Z, Gao R, et al. Prevalence of overweight, obesity, abdominal obesity and obesity-related risk factors in southern China. PLOS ONE 201712 e0183934. (https://doi.org/10.1371/journal.pone.0183934)

14 Yang W, Lu J, Weng J, Jia W, Ji L, Xiao J, Shan Z, Liu J, Tian H, Ji Q et al. Prevalence of diabetes among men and women in China. New England Journal of Medicine 2010362 1090-1101. (https://doi. org/10.1056/NEJMoa0908292)

15 Zhang X, Ran X, Xu Z, Cheng Z, Shen F, Yu Y, Gao L, Chai S, Wang C, Liu J, et al. Epidemiological characteristics of lower extremity arterial disease in Chinese diabetes patients at high risk: a prospective, multicenter, cross-sectional study. Journal of Diabetes and its Complications 201832 150-156. (https://doi.org/10.1016/j. jdiacomp.2017.10.003)

16 Huo X, Gao L, Guo L, Xu W, Wang W, Zhi X, Li L, Ren Y, Qi X, Sun $Z$, et al. Risk of non-fatal cardiovascular diseases in early-onset versus late-onset type 2 diabetes in China: a cross-sectional study.
Lancet: Diabetes and Endocrinology 20164 115-124. (https://doi. org/10.1016/S2213-8587(15)00508-2)

17 Ji L, Hu D, Pan C, Weng J, Huo Y, Ma C, Mu Y, Hao C, Ji Q Ran X, et al. Primacy of the 3B approach to control risk factors for cardiovascular disease in type 2 diabetes patients. American Journal of Medicine 2013126 925.e11-925.e22. (https://doi.org/10.1016/j. amjmed.2013.02.035)

18 Li L, Ji L, Guo X, Ji Q, Gu W, Zhi X, Li X, Kuang H, Su B, Yan J, et al. Prevalence of microvascular diseases among tertiary care Chinese with early versus late onset of type 2 diabetes. Journal of Diabetes and its Complications 201529 32-37. (https://doi.org/10.1016/j. jdiacomp.2014.08.010)

19 Lyu Y, Luo Y, Li C, Guo X, Lu J, Wu H, Huo X, Gu W, Yang G, Ji L, et al. Regional differences in the prevalence of coronary heart disease and stroke in patients with type 2 diabetes in China. Journal of Clinical Endocrinology and Metabolism 2018103 3319-3330. (https:// doi.org/10.1210/jc.2018-00422)

20 Chen C, Lu FC \& Department of Disease Control Ministry of Health, PR China. The guidelines for prevention and control of overweight and obesity in Chinese adults. Biomedical and Environmental Sciences 200417 1-36 (Supplement).

21 Kautzky-Willer A, Harreiter J \& Pacini G. Sex and gender differences in risk, pathophysiology and complications of type 2 diabetes mellitus. Endocrine Reviews 201637 278-316. (https://doi. org/10.1210/er.2015-1137)

22 Ito H, Ohshima A, Ohto N, Ogasawara M, Tsuzuki M, Takao K, Hijii C, Tanaka H \& Nishioka K. Relation between body composition and age in healthy Japanese subjects. European Journal of Clinical Nutrition 200155 462-470. (https://doi.org/10.1038/sj.ejcn.1601206)

23 Bazzocchi A, Diano D, Ponti F, Andreone A, Sassi C, Albisinni U, Marchesini G \& Battista G. Health and ageing: a cross-sectional study of body composition. Clinical Nutrition 201332 569-578. (https:// doi.org/10.1016/j.clnu.2012.10.004)

24 Carr MC \& Brunzell JD. Abdominal obesity and dyslipidemia in the metabolic syndrome: importance of type 2 diabetes and familial combined hyperlipidemia in coronary artery disease risk. Journal of Clinical Endocrinology and Metabolism 200489 2601-2607. (https:// doi.org/10.1210/jc.2004-0432)

25 Henche SA, Torres RR \& Pellico LG. An evaluation of patterns of change in total and regional body fat mass in healthy Spanish subjects using dual-energy X-ray absorptiometry (DXA). European Journal of Clinical Nutrition 200862 1440-1448. (https://doi. org/10.1038/sj.ejcn.1602883)

26 Hillier TA \& Pedula KL. Characteristics of an adult population with newly diagnosed type 2 diabetes: the relation of obesity and age of onset. Diabetes Care 200124 1522-1527. (https://doi.org/10.2337/ diacare.24.9.1522)

27 LeRoith D, Biessels GJ, Braithwaite SS, Casanueva FF, Draznin B, Halter JB, Hirsch IB, McDonnell ME, Molitch ME, Murad MH, et al. Treatment of diabetes in older adults: an Endocrine Society* clinical practice guideline. Journal of Clinical Endocrinology and Metabolism 2019104 1520-1574. (https://doi.org/10.1210/jc.2019-00198)

28 Rawshani A, Rawshani A, Franzén S, Sattar N, Eliasson B, Svensson AM, Zethelius B, Miftaraj M, McGuire DK, Rosengren A, et al. Risk factors, mortality, and cardiovascular outcomes in patients with type 2 diabetes. New England Journal of Medicine 2018379 633-644. (https://doi.org/10.1056/NEJMoa1800256)

Received in final form 12 January 2021

Accepted 2 February 2021

Accepted Manuscript published online 6 February 2021 https://ec.bioscientifica.com https://doi.org/10.1530/EC-20-0547
(C) 2021 The authors Published by Bioscientifica Ltd

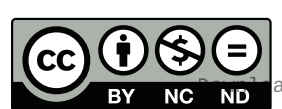

This work is licensed under a Creative Commons Attribution-NonCommercial-NoDerivatives 4.0 International License ifica com at $04 / 26 / 2023$ 01:38:39Am 